\title{
SYNTHESIS AND EVALUATION OF AMINO ACID ESTER CONJUGATES OF HIV PROTEASE INHIBITOR
}

\author{
CHABUKSWAR AR ${ }^{1}$, PREETI M. GANDHI ${ }^{2 *}$ \\ ${ }^{1}$ Department of Pharmaceutical Chemistry, MAEER's Maharashtra Institute of Pharmacy, Pune, Maharashtra, India. ${ }^{2}$ Department of \\ Pharmaceutical Chemistry, JSPM's Jayawantrao Sawant College of Pharmacy and Research, Pune, Maharashtra, India. \\ Email: preetigandhi2007@gmail.com
}

Received: 10 April 2019, Revised and Accepted: 07 May 2019

ABSTRACT

Objective: Ester conjugates of HIV protease inhibitor, lopinavir (LP) with various amino acids were synthesized to improve its physicochemical and pharmacokinetic profile and consequently therapeutic potential.

Materials and Methods: Conjugates of LP with amino acids; glycine, alanine, valine, and serine were prepared by dicyclohexylcarbodiimide coupling method. The synthesized compounds were characterized by nuclear magnetic resonance, mass, and Fourier-transform infrared spectroscopy and evaluated for their solubility, partition coefficient, hydrolytic stability, cytotoxicity, and permeability through Caco-2 cells.

Results: Aqueous solubility studies indicated significantly better solubility profiles of all conjugates as compared to LP. With respect to hydrolysis, all the conjugates displayed higher stability under acidic conditions while undergo hydrolysis with rise in pH. Conjugates did not exhibit cytotoxicity for concentration as high as $100 \mu \mathrm{g} / \mathrm{ml}$, which indicates promising therapeutic potential. Absorptive diffusion of drug across Caco-2 cell monolayers was improved by amino acid conjugation.

Conclusion: Amino acid ester conjugates of LP not only showed better solubility but also significantly higher permeability than LP. Thus, direct conjugation of L-amino acids is a viable approach to improve oral absorption and thereby oral bioavailability of protease inhibitors.

Keywords: Amino acids, Conjugates, HIV, Hydrolysis, Lopinavir, Solubility.

(C) 2019 The Authors. Published by Innovare Academic Sciences Pvt Ltd. This is an open access article under the CC BY license (http://creativecommons. org/licenses/by/4. 0/) DOI: http://dx.doi.org/10.22159/ajpcr.2019.v12i6.33521

\section{INTRODUCTION}

Several strategies have been adopted for the effective treatment of HIV/AIDS since 1984. At present, the greatest success in the clinical management of HIV/AIDS has been observed with the use of antiretroviral drugs such as reverse transcriptase inhibitors and protease inhibitors (PIs). HIV PIs represent an important class of antiHIV drugs in highly active antiretroviral therapy regimen. Although highly active, several unfavorable physicochemical and pharmacokinetic (PK) parameters limit their efficacy. Lopinavir (LP) is potent and one of the frequently administered PIs in the treatment of the HIV [1]. LP is classified as a BCS II drug (high permeability/low solubility). It has very poor bioavailability when administered orally which is due to low water solubility, limited intestinal uptake due to P-glycoprotein efflux and high first-pass metabolism by cytochrome P450 [2-5]. Hence to improve bioavailability, in most of the marketed formulations, it is given in combination with low-dose ritonavir (RTV) because RT is a well-known potent inhibitor of both P-gp and CYP3A [6-8]. However, coadministration of RT with other PIs leads to major adverse effects such as rise in lipid level, glucose, as well as gastrointestinal intolerance [9]. Hence, ritonavir free formulation strategy is needed.

Various strategies have been employed to inhibit both efflux and metabolism to improve oral absorption of PIs. Most common approaches used are coadministration of P-gp and MRP2 substrates with efflux inhibitors and a non-substrate strategy involving chemical modification of compounds such that efflux/metabolism is avoided. Transporter-targeted conjugate or prodrug derivatization is one of the non-substrate strategies which involve utilization of influx transporters facilitating transport of polar nutrients such as amino acids and peptides $[10,11]$. This strategy has been successfully used in an attempt to increase absorption of poorly absorbed drugs such as acyclovir [12], ganciclovir [13-15], saquinavir [16], and zanamivir [17]. Conjugates can be designed by coupling amino acids/peptides to compounds in such a way that they resemble the intestinal nutrients structurally and get easily absorbed by specific carrier proteins. Additional advantage of preparing such conjugates is the formation of non-toxic nutrient molecules when prodrugs are converted to parent drug and promoieties. As amino acids are biocompatible and easily ionizable, they have been widely used as pro-moieties in synthesis of prodrugs [18].

In the present study, conjugates of LP with amino acids, namely glycine, alanine, valine, and serine were synthesized with a simple esterification process to examine the effect of amino acids on solubility and in circumventing P-gp-mediated cellular efflux of LP. The synthesized conjugates were characterized by spectral data (ultraviolet [UV], IR, proton magnetic resonance, and mass) and evaluated for solubility, hydrolytic stability, and cytotoxicity. Transport studies were conducted in Caco-2 cells to compare permeability of conjugates with LP since efflux proteins (Pgp and MRP2) and peptide transporters are well expressed and characterized in Caco- 2 cells.

\section{MATERIALS AND METHODS}

Materials

LP was obtained from Lupin Pharma Ltd. (Pune, India). Boc amino acids, dimethylaminopyridine and N, N'-dicyclohexylcarbodiimide, as well as all other reagents and solvents were commercially procured from Loba Chemicals Pvt. Ltd. (Mumbai, India). The purity of the synthesized compounds was confirmed by thin-layer chromatography (TLC) using precoated TLC plates (Merck, $20 \times 20$, 60F 254). Melting points were recorded in open capillary tubes and 
are uncorrected. Fourier transform infrared (FTIR) spectra were recorded in Bruker FTIR spectrometer (Model - Alpha). ${ }^{1} \mathrm{H}$ nuclear magnetic resonance (NMR) spectra were recorded using Bruker AVANCE III $500 \mathrm{MHz}$ (AV 500) multinuclei solution NMR spectrometer using $\mathrm{CDCl}_{3}$ as the solvent and TOPSPIN 3.2 software. Electrospray ionization mass spectra were recorded on Bruker Impact II UHRTOF mass spectrometer system by electron ionization technique. This method used in positive mode gives either $(\mathrm{M}+\mathrm{H})+$ and/or $(\mathrm{M}+\mathrm{Na})+$ signal. The UV spectrophotometer used for determining the partition coefficient and hydrolysis studies of the compounds was Shimadzu-1800 double beam spectrometer.

\section{Methods}

\section{Synthesis of ester conjugates of lopinavir}

Step I: Reaction of Boc protected amino acids with lopinavir

To a well stirred and cooled solution of LP (500 mg, $0.8 \mathrm{mmol})$ in dichloromethane, dimethylaminopyridine $(190 \mathrm{mg}, 1.6 \mathrm{mmol})$ was added to activate the secondary hydroxyl group of LP and continuously stirred for $10 \mathrm{~min}$ at $0^{\circ} \mathrm{C}$ under anhydrous conditions. Then, Boc amino acid (glycine, alanine, valine, and serine, $1.6 \mathrm{mmol}$ ) and $\mathrm{N}$, $\mathrm{N}$-dicyclohexylcarbodiimide (490 mg, $2.4 \mathrm{mmol}$ ) were added to the reaction mixture over $30 \mathrm{~min}$. The reaction mixture was thereafter, allowed to stir at $0^{\circ} \mathrm{C}$ for $1 \mathrm{~h}$ and at room temperature for next $48 \mathrm{~h}$. The reaction mixture was analyzed by TLC to ensure complete conversion of reactants to product. The mixture was filtered and after drying over $\mathrm{Na}_{2} \mathrm{SO}_{4}$, the solvent was evaporated under reduced pressure at room temperature.

Step II: Deprotection of the N-Boc Group

Boc amino acid LP was treated with 1:1 TFA- $\mathrm{CH}_{2} \mathrm{Cl}_{2}$ mixture at $0^{\circ} \mathrm{C}$ for about $2 \mathrm{~h}$. The solvent was evaporated under vacuum. The crude oily product, amino acid-LP, was purified by recrystallization in cold diethyl ether. The reaction scheme for the synthesis of LP-amino acid ester conjugates is shown in Scheme 1.

\section{Characterization of conjugates}

Conjugates were characterized with FTIR, ${ }^{1} \mathrm{H}$ NMR, and mass spectroscopy. The purity was determined using TLCand physicochemical parameters were determined.

\section{Solubility study}

Saturated solutions of drug and conjugates were prepared in distilled water in $25 \mathrm{~mL}$ conical flasks. The sealed flasks were placed in a mechanical shaker at room temperature (RT) for $24 \mathrm{~h}$. and were centrifuged for $10 \mathrm{~min}$ to separate undissolved conjugates. The supernatant was separated, filtered, and analyzed by UV spectrophotometer at $259 \mathrm{~nm}$ after appropriate dilutions. The samples were studied in triplicate and the results were presented as the mean values $[19,20]$.

\section{Determination of partition coefficient}

The partition coefficient of the LP and synthesized conjugates was determined by shake flask method in n-octanol and water. The drug/ conjugate $10 \mathrm{mg}$ was added to $10 \mathrm{ml}$ of aqueous phase followed by addition of $10 \mathrm{ml}$ of $\mathrm{n}$-octanol. The contents were thoroughly shaken for $2 \mathrm{~h}$ at room temperature and left for $1 \mathrm{~h}$. The conjugate concentration in aqueous phase and organic phase was determined by UV spectrophotometer at $259 \mathrm{~nm}$ and partition coefficient was calculated [21]

\section{In vitro hydrolysis}

The hydrolysis kinetics of conjugates was studied in aqueous buffer solution at $\mathrm{pH} 1.2$ and $\mathrm{pH} 7.4$ at $37^{\circ} \mathrm{C}$ using hydrochloric acid and phosphate buffer, respectively. Solutions of $10 \mathrm{mg}$ of conjugate prepared in $90 \mathrm{~mL}$ of hydrochloric acid buffer $(\mathrm{pH} 1.2)$ or phosphate buffer (pH 7.4) were kept in screw-capped tubes and then placed in shaking water bath $(60 \mathrm{rpm})$ at $37^{\circ} \mathrm{C}$. At predetermined time points, aliquots were withdrawn from tubes and analyzed by UV spectrophotometer for the amount of drug released after the hydrolysis of prodrugs. Pseudofirst-order rate constants (Kobs) were calculated with equation, Kobs =

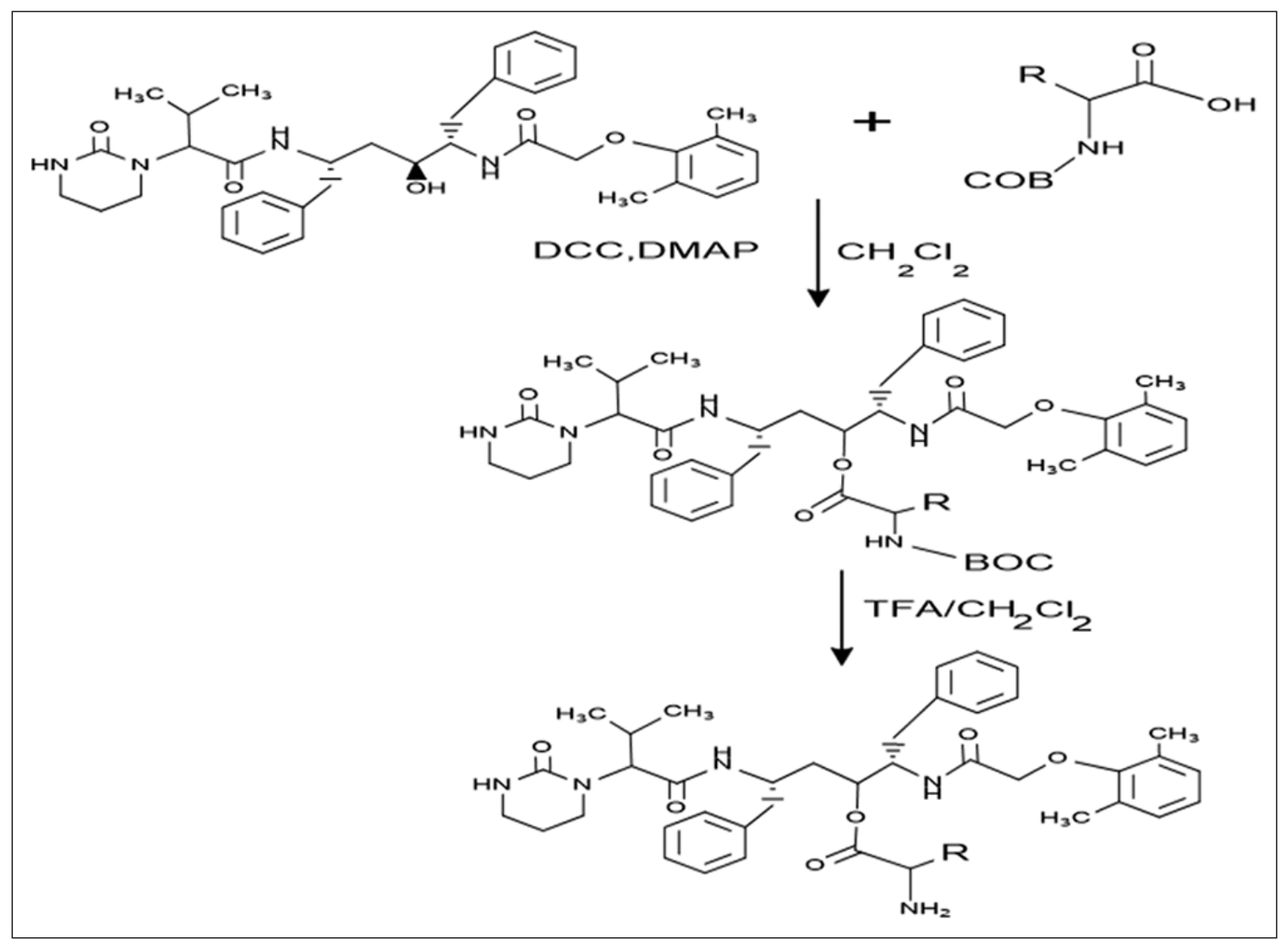

Scheme 1: Scheme for synthesis of lopinavir ester conjugates. $\mathrm{R}=\mathrm{H},-\mathrm{CH}_{3},-\mathrm{CH}\left(\mathrm{CH}_{3}\right)_{2},-\mathrm{CH}_{2} \mathrm{OH}$ (glycine, alanine, valine, and serine) 
$2.303 / \mathrm{t} \times \log (\mathrm{a} / \mathrm{a}-\mathrm{x})$, where "a" is initial concentration of conjugate, " $\mathrm{x}$ " is the amount of conjugate hydrolyzed, and " $t$ " is time in minutes. The corresponding half-life $(\mathrm{t} 1 / 2)$ was then obtained from the equation: $\mathrm{t} 1 / 2=0.693 /$ Kobs $[22,23]$.

\section{Cytotoxicity studies}

Cytotoxicity of conjugates was determined in Caco-2 cells by (3-(4, 5-dimethylthiazol-2-yl)-2,5-diphenyl tetrazolium bromide (MTT) assay based cytotoxicity kit. MTT is a pale yellow substrate which is cleaved by living cells to yield a dark blue formazan product. The amount of MTT cleaved is directly proportional to the number of viable cells present. Briefly, the compounds were dissolved in dimethyl sulfoxide (DMSO) and diluted with complete medium to a range of test concentration. DMSO concentration was kept $<0.1 \%$ in all the samples. Caco2 cells were seeded in 96-well plates and treated with different concentrations of the test samples $(5-200 \mu \mathrm{g} / \mathrm{ml})$ and incubated at $37^{\circ} \mathrm{C}$ for $4 \mathrm{~h}$. MTT reagent was added to each well and incubated for $2 \mathrm{~h}$ at $37^{\circ} \mathrm{C}$. The dark blue formazan product formed by the cells was dissolved in DMSO and absorbance was read at $550 \mathrm{~nm}$.

\section{Permeability/transport studies}

Transport studies were conducted with Caco-2 cell monolayers grown on 12 well Transwell ${ }^{\circledR}$ inserts. Cell monolayers were washed with Dulbecco's phosphate buffered saline (pH 7.4) twice for $15 \mathrm{~min}$ at $37^{\circ} \mathrm{C}$. Transport studies were conducted across Caco- 2 cells for a period of $3 \mathrm{~h}$ at $37^{\circ} \mathrm{C}$. For determining apical-to-basolateral permeability (AB), $0.5 \mathrm{~mL} \mathrm{LP}$ or conjugate solution was added to the apical chamber of 12-well Transwell ${ }^{\circledR}$ plates while the basolateral side of the inserts contained $1.5 \mathrm{ml}$ volume of transport buffer. Aliquots were withdrawn at predetermined time intervals $(30,60,120$, and $180 \mathrm{~min})$ from the receiver chamber and replaced with fresh DPBS pH 7.4 to maintain sink conditions. The concentrations of the test compounds in the transport medium were immediately analyzed by UV spectrophotometer at a wavelength of $259 \mathrm{~nm}$ [24].

The apical-to-basolateral permeability coefficient (Papp in $\mathrm{cm} /$ second) was calculated according to the following equation:

$$
\mathrm{P}_{\mathrm{app}}=\frac{\Delta \mathrm{Q}}{\Delta \mathrm{t}} \times \frac{1}{\mathrm{~A} \times \mathrm{C}_{\mathrm{o}}}
$$

Where, $\Delta \mathrm{Q} / \Delta \mathrm{t}$ is the rate of drug/conjugate flux (mol/s) from donor into the receiver compartment at steady state, $\mathrm{A}$ - the monolayer area $\left(\mathrm{cm}^{2}\right)$, and $\mathrm{C}_{0}$ - the initial concentration of drug/conjugate in apical compartment (mg/mL) [25].

\section{Statistical analysis}

Solubility, buffer stability, and cytotoxicity study results were expressed as mean \pm standard deviation; Student's $t$-test was applied to determine the statistical significance among groups. $\mathrm{P} \leq 0.05$ was considered statistically significant.

\section{RESULTS AND DISCUSSION}

\section{Chemistry}

The LP ester conjugates were synthesized by the dicyclohexylcarbodiimide coupling method. Amino acids, glycine, alanine, valine, and serine were identified as carriers for the synthesis of LP ester conjugates. All conjugates were subjected to solubility, physicochemical characterization, and hydrolytic studies. Purity of the synthesized prodrugs was ascertained by melting point and TLC. The products were obtained in good yields $(78 \%-90 \%)$. The structures of compounds were confirmed by FTIR, $1 \mathrm{H}$ NMR, and mass spectroscopic data. The IR spectra of these compounds show characteristics $C=0$ stretching bands around $1731-1750 \mathrm{~cm}^{-1}$ and C-O stretching bands around $1237-1243 \mathrm{~cm}^{-1}$ for the ester functionality. The $1 \mathrm{H}$ NMR spectra of synthesized conjugates show the chemical shift values and signals characteristic to the functionalities of the amino acids, leading to the confirmation of the structures assigned to the target conjugates.
The mass spectroscopic analysis gives the $(\mathrm{M}+\mathrm{H})^{+}$peak confirming molecular weight of the targeted compounds.

\section{Spectral data}

(2S,5S)-2-(2-(2,6-dimethylphenoxy)acetamido)-5-(3-methyl2-(2-oxotetrahydropyrimidin-1(2H)-yl)butanamido)-1,6diphenylhexan-3-yl glycinate lopinavir glycine conjugate (LPG)

\%Yield: 90.1; Low melting solid; UV ( $\lambda \max )$ : $(\mathrm{MeOH}) 261 \mathrm{~nm}$, IR $\left(\mathrm{cm}^{-1}\right)$ : 3342.74 (N-H str. amine), 3029.75(C-H str. aromatic), 1750.03 (C = O str. ester), 1237.49 (C-0 str. ester), 1558.02 (C = C str. aromatic) 1444.7 $\mathrm{H}-\mathrm{C}-\mathrm{H}$ Bend (asymmetric bend,-CH3) ${ }^{1} \mathrm{H}$ NMR $\left(500 \mathrm{MHz}, \mathrm{CDCl}_{3}\right) \delta 0.75-$ $0.86(\mathrm{~m}, 6 \mathrm{H}), 1.25-1.32(\mathrm{~m}, 2 \mathrm{H}), 1.68-1.71(\mathrm{~d}, 2 \mathrm{H}), 1.88-1.90(\mathrm{~d}, 2 \mathrm{H})$, 2.87-2.88 (m, 2H), 3.17-3.21 (m,3H), 3.64-3.69 (m, 2H), 3.71-3.85 $(\mathrm{m}, 3 \mathrm{H}), 6.85-7.10(\mathrm{~m}, 3 \mathrm{H}), 7.14-7.34(\mathrm{~m}, 10 \mathrm{H})$ electrospray ionization mass spectrometry (ESI-MS): $686.4(\mathrm{M}+\mathrm{H})^{+}$.

(2S,5S)-2-(2-(2,6-dimethylphenoxy)acetamido)-5-(3-methyl2 -(2-oxotetrahydropyrimidin-1(2H)-yl)butanamido)-1,6diphenylhexan-3-yl alaninate lopinavir alanine conjugate (LPA) \%Yield: 87.4; Low melting solid; UV ( $\lambda \max ):(\mathrm{MeOH}) 259 \mathrm{~nm}, \mathrm{IR}\left(\mathrm{cm}^{-1}\right)$ : 3327.92 (N-H str. amine), 2927.44 (C-H str. aromatic), 1731.49 (C = O str. ester), 1237.52 (C-0 str. ester), 1521.50 (C = C str. aromatic) 1447.91 $\mathrm{H}-\mathrm{C}-\mathrm{H}$ Bend (asymmetric bend,-CH3) ${ }^{1} \mathrm{H}$ NMR $\left(500 \mathrm{MHz}, \mathrm{CDCl}_{3}\right) \delta 0.80-$ $0.85(\mathrm{~d}, 6 \mathrm{H}), 1.25$ (d, 3H), 1.72-1.75(d, 2H), 1.88-1.91(m,2H), 2.15-2.18 (m, 6H), 2.71-2.87 (m,4H), $2.90(\mathrm{~d}, 2 \mathrm{H}) 3.12-3.19(\mathrm{~m}, 2 \mathrm{H}), 6.69-6.71(\mathrm{~d}$, $1 \mathrm{H}), 6.85-6.87(\mathrm{~d}, 3 \mathrm{H}), 6.96-7.28(\mathrm{~m}, 10 \mathrm{H})$ ESI-MS: $700.4(\mathrm{M}+\mathrm{H})^{+}$.

(2S,5S)-2-(2-(2,6-dimethylphenoxy)acetamido)-5-(3-methyl2-(2-oxotetrahydropyrimidin-1(2H)-yl)butanamido)-1,6diphenylhexan-3-yl valinate lopinavir valine conjugate (LPV)

\%Yield: 85.7; Low melting solid; UV ( $\lambda$ max): $(\mathrm{MeOH}) 260 \mathrm{~nm}$, IR $\left(\mathrm{cm}^{-1}\right)$ : 3320.06 (N-H str. amine), 3066.04 (C-H str. aromatic), 1735.32 (C = 0 str. ester), 1243.00 (C-0 str. ester), 1516.58(C = C str. aromatic),1446.18 $\mathrm{H}-\mathrm{C}-\mathrm{H}$ Bend (asymmetric bend,-CH3) ${ }^{1} \mathrm{H}$ NMR $\left(500 \mathrm{MHz}, \mathrm{CDCl}_{3}\right) \delta 1.14-$ $1.16(\mathrm{~d}, 6 \mathrm{H}), 1.25-1.34(\mathrm{~d}, 6 \mathrm{H}), 1.72-1.74(\mathrm{~d}, 2 \mathrm{H}), 1.86-1.92(\mathrm{~m}, 6 \mathrm{H})$, $2.11(\mathrm{~s}, 6 \mathrm{H}), 2.27-2.31(\mathrm{~s}, 2 \mathrm{H}), 3.75(\mathrm{~s}, 2 \mathrm{H}), 4.05-4.26(\mathrm{~m}, 2 \mathrm{H}), 4.39(\mathrm{~s}, 1 \mathrm{H})$, 6.71-6.82 (m, 3H), 6.95-7.27(m, 10H) ESI-MS: $728.4(\mathrm{M}+\mathrm{H})^{+}$.

(2S,5S)-2-(2-(2,6-dimethylphenoxy)acetamido)-5-(3-methyl2-(2-oxotetrahydropyrimidin-1(2H)-yl)butanamido)-1,6diphenylhexan-3-yl serinate lopinavir serine conjugate (LPS)

\%Yield: 78.5; Low melting solid; UV ( $\lambda$ max): $(\mathrm{MeOH}) 261 \mathrm{~nm}$, IR $\left(\mathrm{cm}^{-1}\right)$ : 3320.42 (N-H str. amine), 2928.76 (C-H str. aromatic), 1739.34 (C = 0 str. ester), 1239.23 (C-0 str. ester), 1565.58 (C = C str. aromatic) 1446.18 $\mathrm{H}-\mathrm{C}-\mathrm{H}$ Bend (asymmetric bend,-CH3) ${ }^{1} \mathrm{H}$ NMR $\left(500 \mathrm{MHz}, \mathrm{CDCl}_{3}\right) \delta 0.81-$ $0.83(\mathrm{~d}, 6 \mathrm{H}), 1.72-1.75(\mathrm{~d}, 2 \mathrm{H}), 1.90-1.92(\mathrm{~d}, 2 \mathrm{H}), 2.12-2.19(\mathrm{~m}, 1 \mathrm{H})$, $2.29(\mathrm{~s}, 2 \mathrm{H}), 3.03-3.10(\mathrm{~m}, 3 \mathrm{H}), 3.18-3.20(\mathrm{~m}, 1 \mathrm{H}), 3.50-3.43(\mathrm{~m}, 2 \mathrm{H})$, $3.70(\mathrm{~s}, 2 \mathrm{H}), 6.71-6.72(\mathrm{~d}, 1 \mathrm{H}), 6.93-7.00(\mathrm{~m}, 2 \mathrm{H}), \quad 7.13-7.17(\mathrm{~m}, 1 \mathrm{H})$, 7.20-7.30(m,10H) ESI-MS: $716.4(\mathrm{M}+\mathrm{H})^{+}$.

\section{Solubility and partition coefficient}

Solubility studies were carried out in distilled water. All amino acid conjugates exhibited higher solubility compared to parent drug. The observed increase in aqueous solubility of the investigated conjugates was accompanied by a decrease in lipophilicity relative to the parent drug (Table 1). Hence, it is evident that esterification of the hydroxyl group with different amino acids modifies the physicochemical properties of LP. Serine conjugate of LP showed maximum solubility and minimum partition coefficient relative to other amino acid conjugates.

\section{Chemical stability}

Hydrolysis kinetics of LP amino acid conjugates was studied in aqueous buffer solution at $\mathrm{pH} 1.2$ and $\mathrm{pH}$ 7.4. Conjugates showed negligible hydrolysis in acidic buffer solution (data not shown) compared to phosphate buffer $\mathrm{pH}$ 7.4. All the conjugates displayed higher stability under acidic conditions while undergo base-catalyzed hydrolysis. The 
Table 1: Physicochemical and kinetic data of lopinavir and its conjugates in aqueous phosphate buffer solution

\begin{tabular}{|c|c|c|c|c|c|c|c|}
\hline \multirow[t]{2}{*}{ Compound } & \multirow[t]{2}{*}{ Molecular formula } & \multirow[t]{2}{*}{ Molecular weight } & \multirow[t]{2}{*}{ Rf value* } & \multirow[t]{2}{*}{$\log p$} & \multirow[t]{2}{*}{ Solubility $(\mathrm{mg} / \mathrm{ml})$} & \multicolumn{2}{|l|}{ pH 7.4} \\
\hline & & & & & & Kobs $\left(h^{-1}\right)$ & $\mathrm{t} 1 / 2(\mathrm{~h})$ \\
\hline LP & $\mathrm{C}_{38} \mathrm{H}_{52} \mathrm{~N}_{6} \mathrm{O}_{7}$ & 628.80 & 0.74 & 5.31 & $0.045 \pm 0.005$ & & \\
\hline LPG & $\mathrm{C}_{40}^{\circ 0} \mathrm{H}_{55} \mathrm{~N}_{7} \mathrm{O}_{8}$ & 685.85 & 0.82 & 3.94 & $0.63 \pm 0.02$ & 0.1394 & $4.97 \pm 0.2$ \\
\hline LPA & $\mathrm{C}_{41}^{4} \mathrm{H}_{57} \mathrm{~N}_{7} \mathrm{O}_{8}$ & 699.87 & 0.83 & 3.16 & $0.59 \pm 0.01$ & 0.1239 & $5.59 \pm 0.4$ \\
\hline LPV & $\mathrm{C}_{43} \mathrm{H}_{61} \mathrm{~N}_{7} \mathrm{O}_{8}$ & 727.93 & 0.85 & 4.09 & $0.90 \pm 0.06$ & 0.1136 & $6.10 \pm 0.4$ \\
\hline LPS & $\mathrm{C}_{40}^{43} \mathrm{H}_{53} \mathrm{~N}_{5} \mathrm{O}_{7}^{8}$ & 715.87 & 0.79 & 3.02 & $1.35 \pm 0.12$ & 0.1283 & $5.40 \pm 0.3$ \\
\hline
\end{tabular}

*Mobile phase for Thin layer chromatography of lopinavir and its conjugates is ethyl acetate: methanol (9.8:0.2). TLC: Thin-layer chromatography, LP: Lopinavir,

LPG: Lopinavir glycine conjugate, LPA: Lopinavir alanine conjugate, LPV: Lopinavir valine conjugate, LPS: Lopinavir serine conjugate

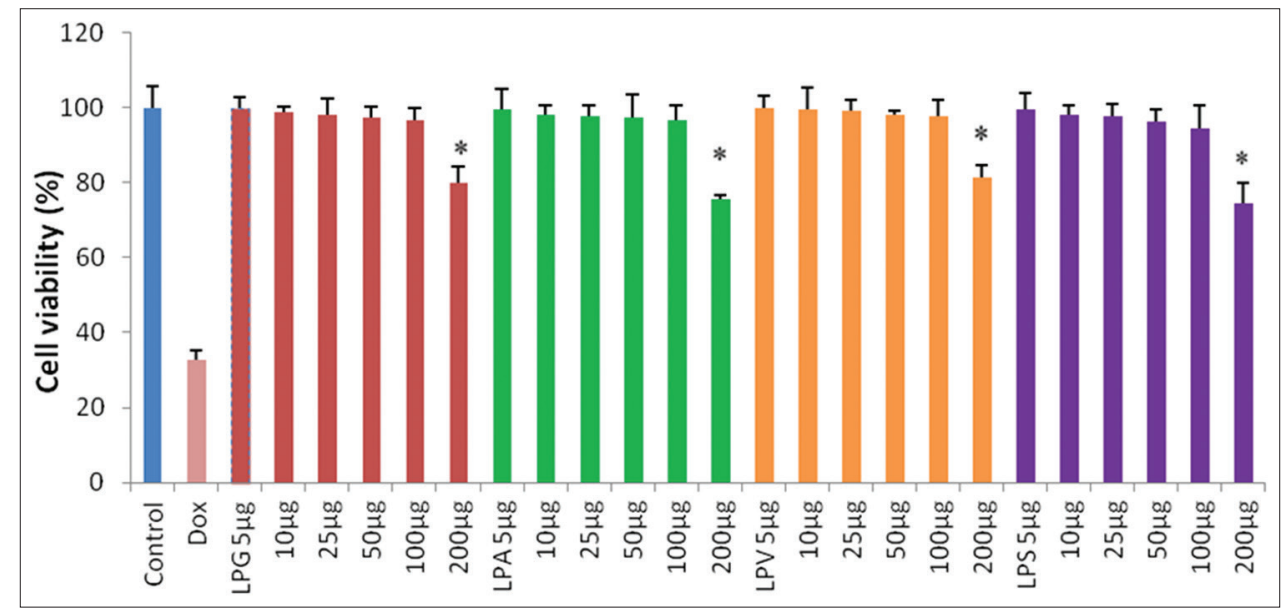

Fig. 1: Cytotoxicity result of lopinavir conjugates in Caco-2 cells. *Statistically significant. $P<0.05$ with respect to control

chemical degradation of ester conjugates of LP followed the first-order kinetics. The rate constants (Kobs) and the corresponding half-lives $\left(\mathrm{t}_{1} / \mathrm{z}_{2}\right)$ for the respective conjugates were calculated from the linear regression equations correlating the log concentration of the residual conjugates versus time. The results are summarized in Table 1 . Degradation halflives of conjugates at pH 7.4 ranged between 4.9 and $6.1 \mathrm{~h}$.

\section{Cytotoxicity studies}

Cytotoxicity of conjugates was determined in Caco-2 cells with MTT assay to check their safety. Results obtained from this study are demonstrated in Fig. 1. Blank medium (without any drug) was used as control. Doxorubicin was used as positive control. DMSO concentration was kept $<0.1 \%$ in all the samples. Conjugates did not exhibit any cell cytotoxicity up to a concentration of $100 \mu \mathrm{g} / \mathrm{ml}$. However, they were observed to be significantly cytotoxic at $200 \mu \mathrm{g} / \mathrm{ml}$. Based on these results, to prevent cytotoxic effects of conjugates, permeability studies were carried out at concentrations of $\leq 50 \mu \mathrm{g} / \mathrm{ml}$.

\section{Permeability study}

Human colon adenocarcinoma cell line (Caco-2) is one of most frequently used and best-established cell lines for the determination of drug permeability across intestinal membranes. Caco-2 cells have been reported to express both P-gp and peptide transporters. Hence, the permeability of LP and its ester conjugates was estimated across the apical cell layer of this cell line. Apparent permeability generated by glycine, alanine, valine, and serine conjugates of LP across Caco- 2 cells in A-B direction was $4.5 \times 10^{-5}, 6.1 \times 10^{-5}, 7.0 \times 10^{-5}$ and $3.9 \times 10^{-5} \mathrm{~cm} / \mathrm{s}$, respectively, whereas for LP, it was found to be $2.9 \times 10^{-5} \mathrm{~cm} / \mathrm{s}$. Apicalto-basolateral permeability of LPG, LPA, LPV, and LPS was about 1.6, 2.2, 2.5 and 1.4-fold higher relative to LP (Fig. 2). All the amino acid conjugates tested showed higher permeability compared to LP which may be due to their reduced recognition by efflux carriers (P-gp) compared to LP. This study also indicated that synthesized amino acid ester conjugates are good substrates for the amino acid transporters expressed on the intestinal barrier and, hence, may get translocated efficiently resulting in higher oral bioavailability.

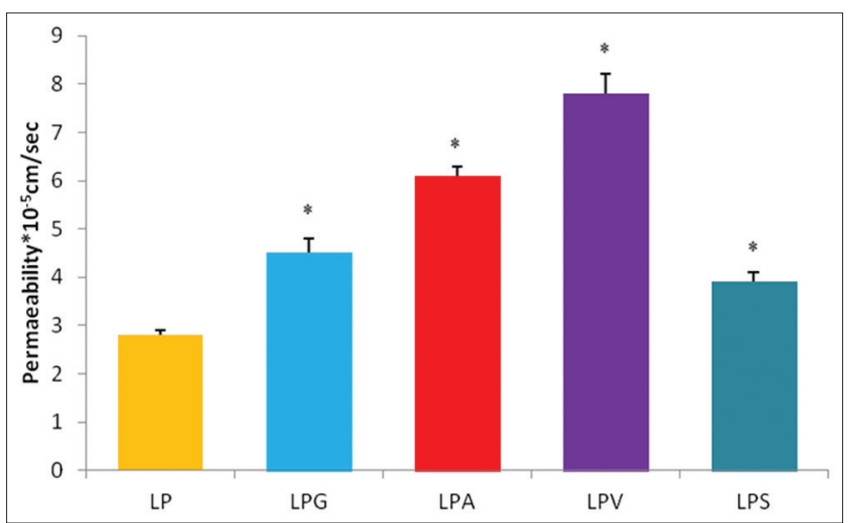

Fig. 2: Permeability of conjugates as compared to drug in Caco2 cells. *Statistically significant. $\mathrm{P}<0.05$ with respect to control (lopinavir)

\section{CONCLUSION}

The present study utilizes amino acids to prepare ester conjugates of LP to improve its physicochemical and PK profile and consequently therapeutic effectiveness. Direct conjugation of amino acids not only improved solubility but also led to enhancement in absorptive flux of LP across Caco- 2 cells. This study confirms that the amino acid conjugation approach has the potential to improve oral absorption and thereby oral bioavailability of PIs.

\section{AUTHORS' CONTRIBUTIONS}

Preeti Gandhi has carried out experiments and analyzed results. Dr. A. R. Chabukswar guided this research work. The authors are thankful to the principal and management of JSPM's Jayawantrao Sawant College of Pharmacy and Research and Maharashtra Institute of Pharmacy, Pune, for providing necessary facilities to carry out present research work. 


\section{CONFLICTS OF INTEREST}

The authors declare that they have no conflicts of interest.

\section{REFERENCES}

1. Cvetkovic RS, Goa KL. Lopinavir/ritonavir: A review of its use in the management of HIV infection. Drugs 2003;63:769-802.

2. Tippabhotla SK, Thudi NR, Raghuvanshi R, Khuroo AH, Gurule S, Mishra S, et al. A bioequivalence study comparing two formulations of lopinavir/ritonavir capsules. Int J Clin Pharmacol Ther 2008;46:204-10.

3. Hsu A, Isaacson J, Brun S, Bernstein B, Lam W, Bertz R, et al. Pharmacokinetic-pharmacodynamic analysis of lopinavir-ritonavir in combination with efavirenz and two nucleoside reverse transcriptase inhibitors in extensively pretreated human immunodeficiency virusinfected patients. Antimicrob Agents Chemother 2003;47:350-9.

4. Agarwal S, Pal D, Mitra AK. Both P-gp and MRP2 mediate transport of lopinavir, a protease inhibitor. Int J Pharm 2007;339:139-47.

5. Kumar GN, Jayanti VK, Johnson MK, Uchic J, Thomas S, Lee RD, et al. Metabolism and disposition of the HIV-1 protease inhibitor lopinavir (ABT-378) given in combination with ritonavir in rats, dogs, and humans. Pharm Res 2004;21:1622-30.

6. Kumar GN, Dykstra J, Roberts EM, Jayanti VK, Hickman D, Uchic J, et al. Potent inhibition of the cytochrome P-450 3A-mediated human liver microsomal metabolism of a novel HIV protease inhibitor by ritonavir: A positive drug-drug interaction. Drug Metab Dispos 1999;27:902-8.

7. Johnson M, Grinsztejn B, Rodriguez C, Coco J, DeJesus E, Lazzarin A, et al. Atazanavir plus ritonavir or saquinavir, and lopinavir/ ritonavir in patients experiencing multiple virological failures. AIDS 2005; 19:685-94.

8. Ribera E, Azuaje C, Lopez RM, Diaz M, Feijoo M, Pou L, et al. Atazanavir and lopinavir/ritonavir: Pharmacokinetics, safety and efficacy of a promising double-boosted protease inhibitor regimen. AIDS 2006;20:1131-9.

9. Shafran SD, Mashinter LD, Roberts SE. The effect of low-dose ritonavir monotherapy on fasting serum lipid concentrations. HIV Med 2005;6:421-5.

10. Agarwal S, Boddu SH, Jain R, Samanta S, Pal D, Mitra AK, et al. Peptide prodrugs: Improved oral absorption of lopinavir, a HIV protease inhibitor. Int J Pharm 2008;359:7-14

11. Patel M, Mandava N, Gokulgandhi M, Pal D, Mitra AK. Amino acid prodrugs: An approach to improve the absorption of HIV-1 protease inhibitor, lopinavir. Pharmaceuticals (Basel) 2014;7:433-52.

12. Dias C, Nashed Y, Atluri H, Mitra A. Ocular penetration of acyclovir and its peptide prodrugs valacyclovir and val-valacyclovir following systemic administration in rabbits: An evaluation using ocular microdialysis and LC-MS. Curr Eye Res 2002;25:243-52.

13. Patel K, Trivedi S, Luo S, Zhu X, Pal D, Kern ER, et al. Synthesis, physicochemical properties and antiviral activities of ester prodrugs of ganciclovir. Int J Pharm 2005;305:75-89.

14. Gunda S, Hariharan S, Mitra AK. Corneal absorption and anterior chamber pharmacokinetics of dipeptide monoester prodrugs of ganciclovir (GCV): In vivo comparative evaluation of these prodrugs with val-GCV and GCV in rabbits. J Ocul Pharmacol Ther 2006;22:465-76

15. Majumdar S, Nashed YE, Patel K, Jain R, Itahashi M, Neumann DM, et al. Dipeptide monoester ganciclovir prodrugs for treating HSV-1induced corneal epithelial and stromal keratitis: In vitro and in vivo evaluations. J Ocul Pharmacol Ther 2005;21:463-74.

16. Jain R, Duvvuri S, Kansara V, Mandava NK, Mitra AK. Intestinal absorption of novel-dipeptide prodrugs of saquinavir in rats. Int $\mathrm{J}$ Pharm 2007;336:233-40.

17. Gupta SV. Enhancing the intestinal membrane permeability of zanamivir: A carrier mediated prodrug approach. Mol. Pharm 2011;8:2358-67.

18. Urendran V, Singh A, Sampathkumar PK. Synthesis and characterization of novel amino acid prodrug of famotidine. Int J Pharm Pharm Sci 2015;7:403-8

19. Mahfouz NM, Hassan MA. Synthesis, chemical and enzymatic hydrolysis and bioavailability evaluation in rabbits of metronidazole amino acid ester prodrugs with enhanced water solubility. J Pharm Pharmacol 2001;53:841-48.

20. Shah N, Seth AK, Balaraman R. Bioavailability enhancement of poorly soluble raloxifene by designing inclusion complex with $\beta$-cyclodextrin. Int J Pharm Pharm Sci 2015;7:205-11.

21. Aggarwal AK, Gupta M. Solubility and solution stability studies of different amino acid prodrugs of bromhexine. Drug Dev Ind Pharm 2012;38:1319-27.

22. Zhao X, Tao X, Wei D, Song Q. Pharmacological activity and hydrolysis behavior of novel ibuprofen glucopyranoside conjugates. Eur J Med Chem 2006;41:1352-8.

23. Dhokchawle BV, Bhandari AB. Synthesis, hydrolysis kinetics and pharmacological evaluation of aceclofenac prodrugs. Antiinflamm Antiallergy Agents Med Chem 2015;13:188-94.

24. Joshi G, Kumar A, Sawant K. Bioavailability enhancement, caco2 cells uptake and intestinal transport of orally administered lopinavirloaded PLGA nanoparticles. Drug Deliv 2016;23:3492-504.

25. Senanayake TH, Warren G, Wei X, Vinogradov SV. Application of activated nucleoside analogs for the treatment of drug-resistant tumors by oral delivery of nanogel-drug conjugates. J Control Release 2013;167:200-9. 